
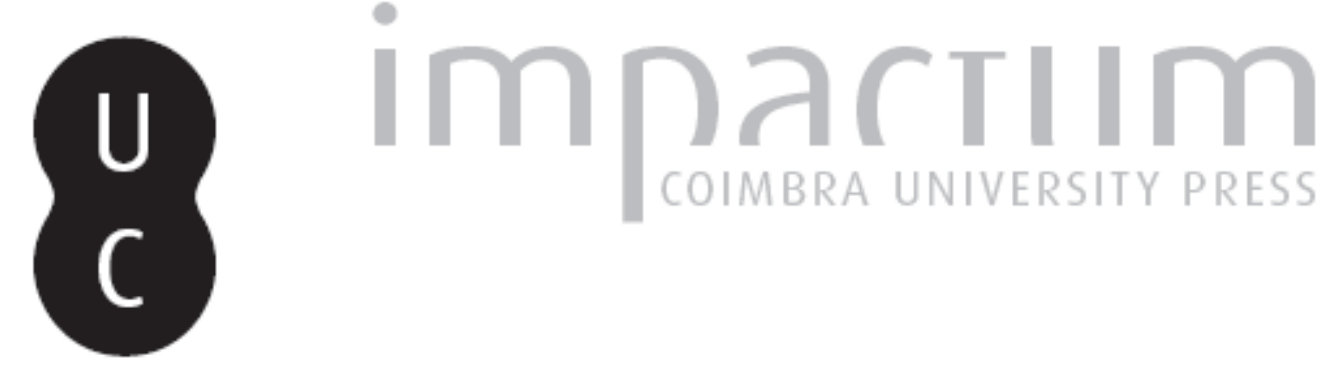

\title{
Os SIG como ferramenta de suporte nos cuidados de saúde primários: caso de estudo na distribuição de enfermeiros de família por área geográfica
}

Autor(es): $\quad$ Fonseca, Luís Carlos Santos; Sousa, Ana Maria Rodrigues Monteiro de

Publicado por: Associação Portuguesa de Riscos, Prevenção e Segurança; Imprensa

URL

persistente:

da Universidade de Coimbra

DOI: $\quad$ DOI:https://doi.org/10.14195/1647-7723_24_11

Accessed : $\quad$ 26-Apr-2023 12:52:59

A navegação consulta e descarregamento dos títulos inseridos nas Bibliotecas Digitais UC Digitalis, UC Pombalina e UC Impactum, pressupõem a aceitação plena e sem reservas dos Termos e Condições de Uso destas Bibliotecas Digitais, disponíveis em https://digitalis.uc.pt/pt-pt/termos.

Conforme exposto nos referidos Termos e Condições de Uso, o descarregamento de títulos de acesso restrito requer uma licença válida de autorização devendo o utilizador aceder ao(s) documento(s) a partir de um endereço de IP da instituição detentora da supramencionada licença.

Ao utilizador é apenas permitido o descarregamento para uso pessoal, pelo que o emprego do(s) título(s) descarregado(s) para outro fim, designadamente comercial, carece de autorização do respetivo autor ou editor da obra.

Na medida em que todas as obras da UC Digitalis se encontram protegidas pelo Código do Direito de Autor e Direitos Conexos e demais legislação aplicável, toda a cópia, parcial ou total, deste documento, nos casos em que é legalmente admitida, deverá conter ou fazer-se acompanhar por este aviso. 


\section{MULTIDISCIPLINARIDADE NA ANÁLISE DAS MANIFESTAÇÕES DE RISCO}

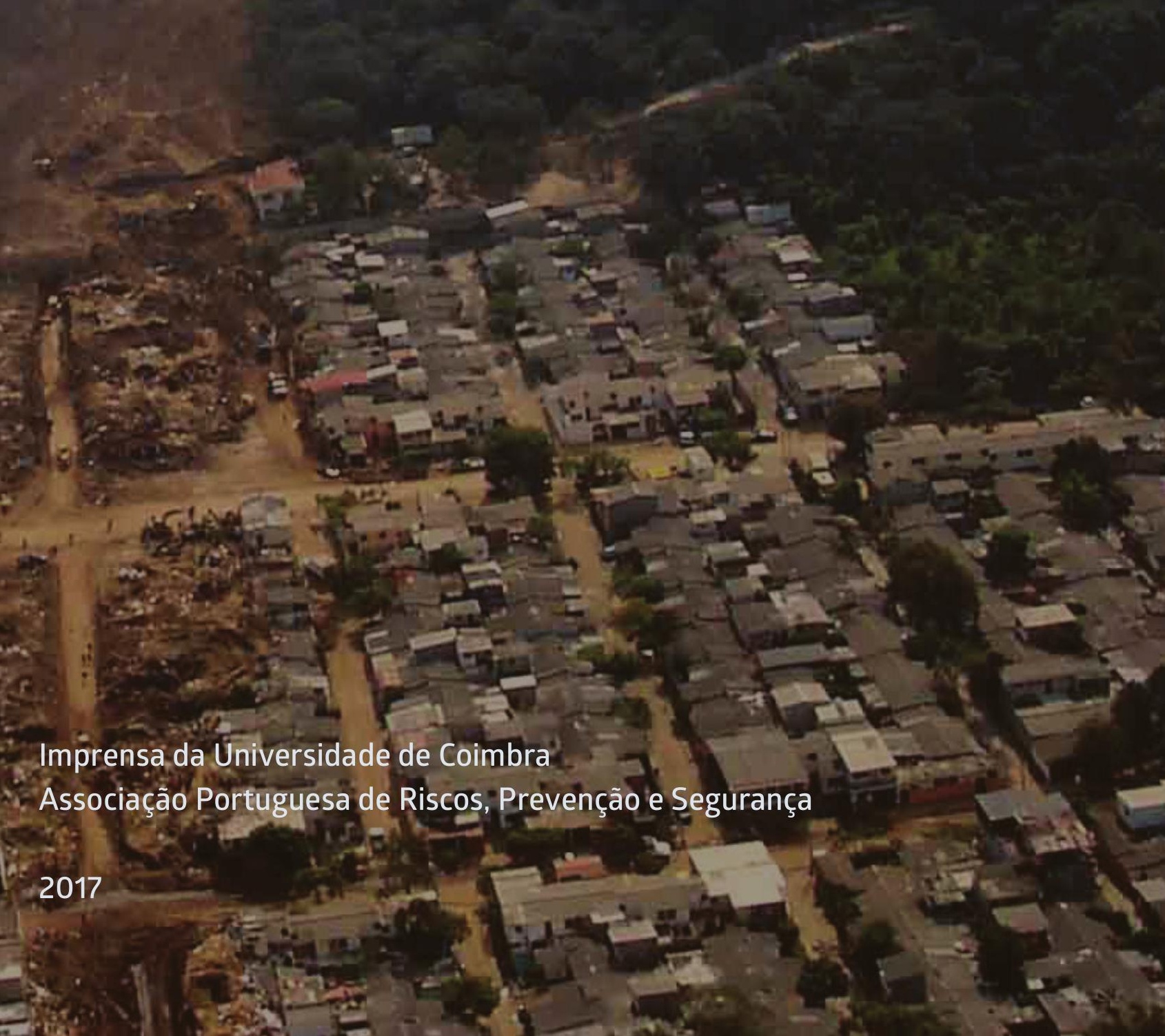




\title{
OS SIG COMO FERRAMENTA DE SUPORTE NOS CUIDADOS DE SAÚDE PRIMÁRIOS: CASO DE ESTUDO NA DISTRIBUIÇÃO DE ENFERMEIROS DE FAMÍLIA POR ÁREA GEOGRÁFICA*
}

\author{
GIS AS A SUPPORT TOOL IN PRIMARY HEALTH CARE: \\ CASE STUDY OF DISTRIBUTION OF FAMILY NURSES BY GEOGRAPHIC AREA
}

Luís Carlos Santos Fonseca

Departamento de Geografia, Faculdade de Letras da Universidade do Porto

Isfonsecaa@gmail.com

Ana Maria Rodrigues Monteiro de Sousa

Departamento de Geografia, Faculdade de Letras da Universidade do Porto CITTAISPUP; ERA URBAN NET; 85NU - PRONUTRISENIOR anamonteirosousa@gmail.com

\section{RESUMO}

Com este trabalho procuramos mostrar o valor acrescentado dos Sistemas de Informação Geográfica (SIG) quando arquitetados e construídos de raiz numa perspetiva sistémica para um fim específico. Neste caso em concreto utilizamos a nossa questão de partida - definição de áreas geográficas homogéneas para a distribuição de enfermeiros de família para a Unidade de Saúde Familiar (USF) da Nova Via pertencente ao Agrupamento de Centros de Saúde de Espinho/Gaia na Área Metropolitana do Porto- para construir um suporte de gestão adaptado à realidade vivida numa Unidade de Saúde Familiar.

Palavras-chave: SIG, georreferenciação, áreas geográficas homogéneas.

\section{ABSTRACT}

With this paper we aim to demonstrate the increased value of Geographic Information System (GIS) when architected and built from scratch with a systemic view for a specific goal. In this specific matter we use our starting question - definition of homogenous geographic areas for the family nurses' distribution in the family health unity of Nova Via appurtenant to the health centers grouping of Espinho/Gaia at the Porto metropolitan region - to build a management support adapted to the living reality at a family health unity.

Keywords: GIS, georeferencing, homogenous geographic areas.

\section{RESUMEN}

Los SIG como herramienta de soporte en la atención primaria de salud. Caso de estudio en la distribución de enfermeros de familia por área geográfica - Este trabajo muestra la plusvalía de los SIG cuando son armados y construidos desde el inicio con un enfoque sistémico para un fin específico. En este caso, utilizando nuestra pregunta de partida - definición de áreas geográficas homogéneas para la distribución de enfermeros de familia en la Unidad de Salud Familiar de Nova Via, que pertenece al Agrupamiento de los Centros de Salud de Espinho/Gaia, en el área metropolitana de Oporto - se construyó un SIG para ser un soporte de gestión adaptado a la realidad vivida en una Unidad de Salud Familiar.

Palabras clave: SIG, georreferenciación, áreas geográficas homogéneas.

\section{RESUMÉ}

Les SIG comme outil de base dans les premiers soins de santé: étude de cas de la distribution des infirmières et infirmiers de famille par zone géographique - A partir de ce travail, nous essayons de démontrer la valeur ajoutée des Systèmes d'information géographique (SIG) architecturés et construits à partir de zéro, dans une perspective systémique pour un usage particulier. Dans ce cas particulier, nous utilisons notre point de départ - la définition des zones géographiques homogènes pour la répartition des infirmières de la famille à l'Unité de santé familiale (USF) Nova Via appartenant aux centres de santé de regroupement de Espinho/Gaia dans la région métropolitaine Porto pour construire un support de gestion adapté à la réalité vécue dans une unité de santé familiale.

Mots-clé: SIG, géoréférencement, zones géographiques homogènes, unité de santé familiale.

* O texto deste artigo foi submetido em 24-11-2015, sujeito a revisão por pares a 09-01-2016 e aceite para publicação em 04-05-2016.

Este artigo é parte integrante da Revista Territorium, n. ${ }^{\circ} 24,2017,{ }^{\circ}$ RIscos, ISSN: 0872-8941. 


\section{Introdução}

Considerando a saúde como o principal bem que qualquer indivíduo pode possuir e que os prestadores de cuidados de saúde primários têm como missão principal prevenir a doença e promover a saúde da forma mais eficiente é indispensável que, ao desenharem as suas estratégias de intervenção, estejam dotados das melhores condições para conhecer e compreender a realidade em que atuam, a população e o território onde oferecem todos os seus serviços.

Atualmente, o Serviço Nacional de Saúde Português (SNS), e em concreto os Agrupamentos de Centros de Saúde (ACES) deparam-se com a necessidade de redimensionar as perspetivas e as escalas de abordagem, sobretudo num período em que a conjuntura socioeconómica do país se encontra debilitada e quando os recursos humanos e financeiros são cada vez mais escassos. Para isso, é crucial ter a capacidade de alargar o leque de informação essencial para que seja possível gerir a prestação de serviços de saúde com mais eficiência e eficácia.

Por tudo isto compreende-se que para o planeamento em saúde a intervenção neste segmento da oferta do SNS é essencial mas também a mais complexa já que não pode envolver apenas competências na área da saúde como acontece noutros níveis. A pluridisciplinaridade é incontornável desde o diagnóstico até à avaliação de resultados passando pela definição dos programas e ações que previnam a doença e promovam a saúde. Há um leque vastíssimo de áreas de saber - geografia, sociologia, psicologia, ciência política, informação e comunicação, economia, ciência do risco, ambiente, etc., que não fazem parte dos quadros funcionais previstos na prestação dos cuidados de saúde primários (Decreto-Lei n. ${ }^{\circ} 88 / 2005$ de 3 de Junho) e que são absolutamente cruciais para implementar a filosofia subjacente à sua criação (Gudes et al., 2011).

A recente reconfiguração dos serviços de saúde surge neste sentido e implica um grande conhecimento e compreensão das características da população e do território onde oferecem todos os seus serviços para que possam tornar a sua atuação na população cada vez mais eficaz. Nesta medida, a atitude a tomar passa por intervenções mais direcionadas e pela maior proximidade à área geográfica de intervenção, reorientado os cuidados de saúde para próximo das comunidades. Assim, a existência de um Enfermeiro de Família por área geográfica (VaughanCole et al., 1998) assume-se fundamental, sendo várias as vantagens já enunciadas (Azevedo et al., 2012), pois este representa um elo de referência entre o serviço de saúde e o utente/família, assumindo a responsabilidade da prestação de cuidados de enfermagem e promovendo um apoio fundamental às questões de saúde e às famílias (Henessy and Glandin, 2006).
O conceito de Enfermeiro de Família, enfatizado na conferência de Munique (WHO, 2000), tem vindo a ser integrado no âmbito dos sistemas de saúde de uma grande parte dos países, reforçando a importância da contribuição da enfermagem para a promoção da saúde e prevenção da doença.

Em Portugal já se encontram definidas as duas principais competências destes profissionais de saúde: i)cuidar da família como unidade de cuidados, promovendo a capacitação da mesma face às exigências e especificidades do seu desenvolvimento; ii) prestar cuidados específicos nas diferentes fases do ciclo de vida da família ao nível da prevenção primária, secundária e terciária, focando-se tanto na família como um todo, quanto nos seus membros individualmente (Regulamento n. ${ }^{\circ} 126 / 2011$ de 18 de Fevereiro de 2011).

Considerando tais competências, entendemos que os Sistemas de Informação Geográfica (SIG) são uma ferramenta que podem auxiliar na atuação destes profissionais e revelar-se de extrema importância para a resolução de vários problemas com que se depara os serviços de saúde.

Os SIG não têm uma definição universal mas sim tantas quantas as possibilidades e ferramentas de tratamento e análise de informação que disponibilizam (Taylor and Overton, 1991). Em síntese integram um vasto conjunto de procedimentos de inserção, armazenamento, manipulação, visualização e exportação de informação geográfica e alfanumérica. Tem como grande vantagem a possibilidade de utilizar qualquer escala geográfica (global, regional e local) e integrar informação proveniente de distintos softwares e variáveis de diferentes escalas, já que toda a informação pode ser georreferenciada (Kemp et al., 2008; Fonseca, 2012). Atualmente apresentam-se sobretudo como um sistema de gestão e apoio à tomada de decisão (Riner et al., 2004; Esteves, 2010).

Estas ferramentas têm sido bastante utilizadas no âmbito da investigação em saúde (Martin et al., 2002) (Kistemann et al., 2002), sendo o primeiro SIG aplicado à saúde consensualmente atribuído a Snow, (Snow, 1849), evidentemente não da forma que os conhecemos hoje mas por mapear a distribuição de mortes por cólera nos quarteirões da cidade de Londres.

Em Portugal, para Área Metropolitana do Porto, vários estudos de saúde têm utilizado o contributo dos SIG para avaliar vulnerabilidade e risco de surgimento e/ou agravamento de algumas patologias (Monteiro et al., 2012a; Monteiro et al., 2012b) em momentos de comportamento excecional da temperatura (Esteves, 2010; Moreira, 2011).

O contributo dos SIG para apoiar a tomada de decisão em diversos domínios é atualmente um facto absolutamente 
inquestionável. Na área da saúde e nomeadamente nos cuidados de saúde primários torna-se premente a necessidade de ferramentas adaptadas que permitam compreender a complexidade do universo alvo da sua atuação (Driedger et al., 2007).

Tendo tomado consciência da importância que a informação espacial tem no âmbito da saúde, os responsáveis estão agora a ampliar o uso dos SIG para visualizarem e analisarem a informação recolhida.

O fato da informação existente nos sistemas de informação de saúde possuírem dados geográficos, como a morada, o código postal, a freguesia, o telefone permite com facilidade explorar e sobrepor essa informação no território e dar assim maior conhecimento da realidade e das relações que de outra forma não são tão facilmente percetíveis (Miranda and Dolinoy, 2005).

Os sistemas de saúde possuem bases de dados muito grandes, bastante complexas que armazenam em diversos sistemas de informação. Esta informação é geralmente usada para identificar os utentes e quais as patologias a eles diagnosticadas enquanto toda a informação espacial é constantemente desvalorizada (Bédard et al., 2003). Isto faz com que geralmente os serviços de saúde sejam ricos em quantidade de dados mas pobres na posse de informação capaz de apoiar a decisão (Cwhpin, 2000).

Como refere (Riner et al., 2004), os profissionais de saúde sempre procuraram mapear as doenças embora com recurso a ferramentas muito simples, porque no decurso da sua experiência profissional, cedo se aperceberam que tanto a prevenção como o tratamento da doença não dependem exclusivamente da prescrição de soluções médicas ou de enfermagem. Donde a recetividade ao uso dos SIG seja muito grande, dada a facilidade de elaboração de mapas com qualidade e a agilidade com que permitem ensaiar diversos cenários de cruzamentos de variáveis há tanto tempo almejada. Atualmente as tecnologias que têm sido cada vez mais aplicadas a esta finalidade são precisamente os SIG, o sensoriamento remoto e sistemas de posicionamento global (Gao, 2010). Um dos exemplos é a ferramenta AccessMod, desenvolvida pela Organização Mundial de Saúde (OMS) e totalmente preparada para ser integrada num SIG de forma a permitir suporte na análise da acessibilidade da rede de serviços de saúde (Ray and Ebener 2008).

O facto de vivermos atualmente numa época em constante mudança de expectativas e valores por parte das pessoas e alvo de profundas e rápidas alterações do território graças à inovação tecnológica, fazem com que a realidade estática traduzida por qualquer mapa se desatualize num curto espaço de tempo e se torne ineficaz. Também neste quadro as características destas ferramentas SIG facilitam bastante a necessidade de corrigir as variáveis em análise e responder em tempo útil a novos cenários (Siffel et al., 2006).
O aumento da efetividade e eficácia das decisões tornou-se imperativo para alcançar as metas contratualizadas pelas instituições de saúde. Nesse contexto, os sistemas de informação para apoio à decisão mostram-se como uma ferramenta particularmente adequada para aperfeiçoar os sistemas de saúde. A qualidade da informação traduzse na qualidade das estratégias e politicas adotadas e influencia a tomada de decisão (Choo, 2006). Acresce que a componente geoespacial permite uma melhor apresentação e visualização dos dados e consequente melhoria na divulgação, comunicação, análise e suporte para a tomada de decisão (Bédard et al., 2003).

Neste quadro, ferramentas como os SIG, associadas ao conhecimento geográfico, podem evidenciar-se como auxílios imprescindíveis no diagnóstico e na análise de uma miríade imensa de variáveis tão diversas.

No caso dos SIG porque a sua aplicação tem demonstrado que facilita o tratamento e estudo de dados, proporcionando uma agilização dos métodos de trabalho, uma maior rapidez na formulação de questões e no encontro de respostas para as problemáticas em análise.

No caso da geografia porque é uma ciência de interface entre as ciências naturais e as ciências sociais cujo objeto é procurar encontrar as organizações espaciais de maior sucesso tendo em conta quer as características sociais e económicas das pessoas, quer as características biogeofísicas do território. É uma ciência que tem por formação competências em diversos códigos de linguagem e que tem uma sólida apetência de mobilidade adequada entre diversas escalas espaciais e temporais.

Uma das características fundamentais destas ferramentas SIG é a confidencialidade, a segurança e privilégios de acesso da informação. Através dos SIG, é também possível aos profissionais de saúde armazenar, partilhar e consultar informação sem violar qualquer norma ética e muito menos sem correr riscos no que toca à segurança dos dados, que no caso da saúde são deverás sensíveis pois representam a saúde e a doença dos cidadãos.

No caso da saúde e em concreto neste momento histórico em que a abordagem pretendida é a holística e sistémica, o presente estudo apresenta com êxito as vantagens dos SIG com um estudo de caso útil para o ACES Espinho/Gaia.

Assim, em síntese os principais benefícios do uso dos SIG no domínio da saúde pública são: i) a capacidade de combinar diferentes conjuntos de dados provenientes de diversas fontes e geri-los de forma adequada permitindo planear melhor as intervenções no domínio da prevenção da doença e promoção da saúde; ii) a variedade de novas ferramentas de tratamento e análise de dados de índole diversa, tais como, sistemas de posicionamento global, imagens de satélite ou fotografias aéreas que podem ser muito úteis tanto para identificar como para explicar 
os focos de algumas patologias; iii) a facilidade com que permitem a partilha de dados e com que importam informação proveniente de outros softwares o que no sistema de saúde é muito importante; iv) a enorme eficiência para apoiar a tomada de decisão, estimulando a comunicação; v) a capacidade de assegurar a manutenção dos registos guardados; vi) a capacidade de permitem o gerenciamento da informação geográfica restringindo o acesso de forma desejada (Elzubair, 2009).

\section{Área de estudo}

No que respeita à implementação do Plano Nacional de Saúde (PNS), Portugal continental está dividido em 5 Administrações Regionais de Saúde que se subdividem em ACES e Unidades Locais de Saúde (ULS) (fig. 1) que gerem os Centros de Saúde, Unidades de Saúde Familiar, Unidades de Cuidados de Saúde Personalizados, Unidade de Recursos Assistenciais Partilhados.

A área de estudo contemplada neste trabalho, à data de 2011, faz parte da Administração Regional de Saúde do Norte (ARS Norte) onde se encontram definidos 24 ACES e 2 ULS (Portaria n. ${ }^{\circ}$ 273/2009, de 18 de março, corrigida pela declaração de retificação $n^{\circ} 32 / 2009$, inserta no DR n94). O ACES selecionado - ACES Espinho/ Gaia - enquadra-se na Área Metropolitana do Porto (AMP) e composto por 23 freguesias distribuídas por três concelhos, Vila Nova de Gaia, Espinho e Gondomar.
Abrange uma área de $159 \mathrm{~km}^{2}$ e de acordo com os censos 2011 tem 183524 habitantes (fig. 1).

Este ACES é composto por 23 extensões de saúde, das quais oito são Unidades de Saúde Familiar - unidades elementares de prestação de cuidados de saúde, individuais e familiares, que assentam em equipas multiprofissionais, constituídas por médicos, por enfermeiros e por pessoal administrativo que têm como missão principal a prestação de cuidados de saúde personalizados à população inscrita de uma determinada área geográfica, garantindo a acessibilidade, a globalidade, a qualidade e a continuidade dos mesmos (Decreto-Lei n. ${ }^{\circ}$ 298/2007 de 22 de agosto).

Para o desenvolvimento deste projeto foi selecionada apenas a Unidade de Saúde Familiar (USF) Nova Via que tem como área geográfica âncora as freguesias da Madalena, de Valadares e de Vilar do Paraíso, todas do concelho de Vila Nova de Gaia. A USF Nova Via é do agrupamento, a que tem maior número total de utentes inscritos, 17711 utentes. Destes somente 14677 (82,9\%) utentes residem nas freguesias da Madalena, Valadares e Vilar do Paraíso.

O enfoque na USF Nova Via resultou por esta ser a USF com maior número de utentes inscritos do ACES, da qualidade dos registos existentes e sobretudo pelo do interesse nos resultados demonstrado pelos responsáveis.
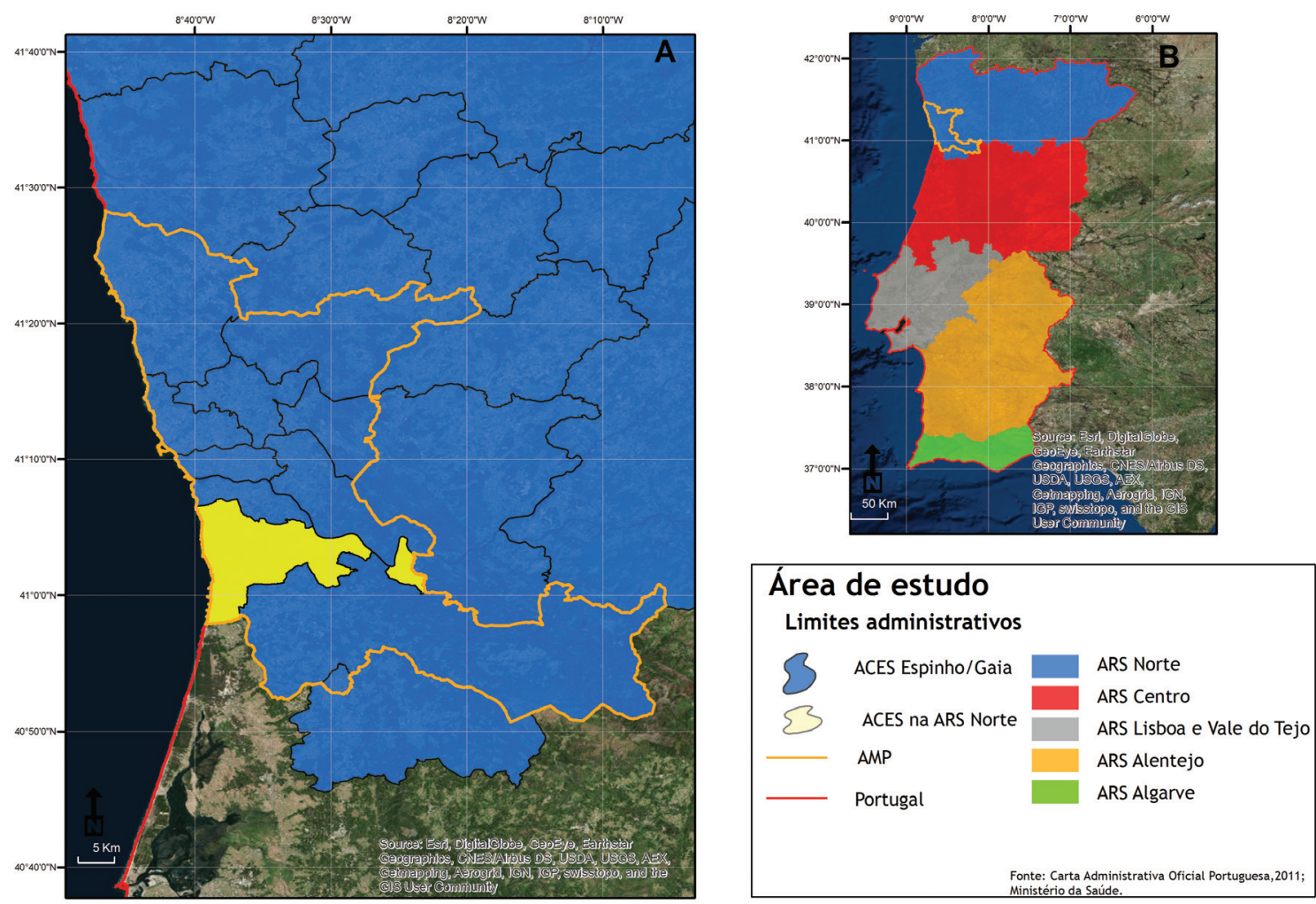

Fig. 1 - Enquadramento do ACES Espinho/Gaia.

Fig. 1 - ACES Espinho/Gaia Framework. 
De acordo com a legislação portuguesa, -Artigo 8 do Decreto-Lei n. ${ }^{\circ}$ 298/2007 de 22 de Agosto - a população inscrita em cada USF não deve ser inferior a 4000 nem superior a 18000 utentes, a USF Nova Via encontra-se na iminência de atingir o número máximo de utentes inscritos. Esta característica ilustra a sua grande atratividade e acentua ainda mais a necessidade de otimizar a gestão dos recursos para procurar manter e, se possível reforçar ainda mais o interesse e a confiança que a população já revela atualmente.

Esta área apresenta características biogeofísicas e socioeconómicas muito distintas, o que prenuncia a necessidade de elaboração e implementação de estratégias muito diversas para cada subgrupo populacional específico. Conhecer e entender o espaço físico que nos rodeia é indispensável para a implementação com sucesso de qualquer medida de política e neste caso em concreto é crucial para promover a qualidade de vida e o bem-estar da população.

\section{Metodologia}

Tendo este panorama como pano de fundo, este trabalho pretende demonstrar a importância dos SIG enquanto ferramenta de gestão e apoio à tomada de decisão nos cuidados de saúde primários.

O objetivo geral deste projeto passou pela delimitação de áreas geográficas para a distribuição de enfermeiros de família para a USF Nova Via que garantam equidade na diversidade de oportunidades e constrangimentos à promoção da saúde através da utilização dos sistemas de informação geográfica.

Procuramos mostrar o valor acrescentado dos SIG quando arquitetados e construídos de raiz numa perspetiva sistémica para um fim específico. Neste caso em concreto utilizamos a nossa questão de partida - definição de áreas geográficas homogéneas para a distribuição de enfermeiros de família para a USF da Nova Via pertencente ao ACES Espinho/Gaia - para construir um suporte de gestão adaptado a uma USF.

Assim, a seleção dos critérios prioritários para a definição das áreas geográficas dos enfermeiros passou a ser considerado um objetivo importante para a plena concretização da estratégia delineada para os cuidados de saúde primários. Todavia, esta escolha envolve uma miríade de saberes que na maioria dos casos não se conjugam no quadro operacional dos ACES.

A concretização do nosso objetivo implicou a utilização de fontes cartográficas e bases de dados de índole muito diversas (INE, SINUS, MIM@UF, IGEO, IGEOE, etc.). Ao mesmo tempo procuramos aproveitar dos softwares SIG utilizados - ArcGis; Batchgeo, GPSVisualizer - todas as ferramentas necessárias para atingir cada uma das metas pré-definidas
Para cumprir este propósito de delimitação de áreas homogéneas para a distribuição dos enfermeiros de família do ACES Espinho/Gaia, destacamos 3 etapas essenciais, i) reunir um vasto e diverso conjunto de informação sobre as características biogeofísicas, socioeconómicas e sobre a história recente de formação do ACES Espinho/Gaia, para assim podermos compreender o território ii) conhecer a população envolvida através da georreferenciação dos utentes inscritos neste agrupamento e iii) analisar a distribuição de determinadas patologias associadas a esses utentes para que fosse possível caracterizar a saúde da população em análise. Após realizadas estas etapas definimos os critérios para a delimitação das áreas. Toda esta informação necessitou de ser reorganizada para ser tratada e armazenada em ambiente SIG sempre sem menosprezar os requisitos de sigilo e confidencialidade que este tipo de informação obriga.

Etapa 1 - recolha de informação biogeofísica e socioeconómica

Para a concretização desta primeira etapa socorremonos principalmente da informação oficial disponível no Instituto Nacional de Estatística (INE), no Instituto Geográfico Português (IGEO), no Instituto Geográfico do Exército (IGEOE) e bases de dados disponibilizadas pelo Projeto de investigação PTDC/SAU-ESA/73016/2006 - Os riscos para a saúde humana causados pelas ondas de calor e vagas de frio no Porto. Toda esta informação permitiu caracterizar e analisar a morfologia, os declives, a litologia, a rede hidrográfica, o clima regional, as exposições solares, a qualidade do ar, as áreas verdes, o edificado, as divisões administrativas, a rede viária, e as características socioeconómicas da população residente na área de estudo.

Etapa 2- georreferenciação dos utentes da USF Nova Via

$\mathrm{Na}$ segunda etapa procedemos à georreferenciação dos 16323 utentes inscritos na USF Nova Via residentes nas 23 freguesias que compõe o ACES. Decidimos tratar a informação sobre os utentes inscritos no ACES Espinho/Gaia, até à data de 30 de setembro de 2011, disponibilizada pelo sistema de informação do agrupamento, o SINUS. A informação foi exportada, em ficheiro texto (.txt). Esta etapa foi bastante morosa e difícil já que o processo administrativo de registo e armazenamento tem um desenho de campos de informação muito desorganizado e confuso. Há atributos idênticos com redação diversa e em alguns campos há mesmo a junção de mais do que um atributo.

No que respeita às moradas verificamos que, quando comparadas com a informação de acessibilidades da ESRI, através da qual foi feito o processo seguinte 
de georreferenciação por morada, beneficiando do protocolo que existe com a Universidade do Porto, a identificação da rua registada no SINUS, não correspondia, em muitos casos, à morada real. Por exemplo, alguns utentes estão registados como residentes numa avenida quando na realidade a designação é rua. $E$ este pormenor faz toda a diferença na atribuição de uma posição no espaço para the associar posteriormente um conjunto variado de atributos. Assim, foi necessário uniformizar individualmente a informação relativa ao tipo de rua para que no processo de georreferenciação o software conseguisse detetar corretamente a morada indicada.

A georreferenciação dos utentes foi elaborada com o recurso a vários softwares de informação geográfica, livres (opensource) e comerciais. Apesar do leque de opções ser considerável a nossa escolha recaiu sobre três softwares: um comercial, o ArcGis, e dois livres, o Batchgeo (disponível on-line em: http://www.batchgeo. com) e o GPSVisualizer (disponível on-line em: http:// www.gpsvisualizer.com/).

O Batchgeo é um software ainda sem grande visibilidade na comunidade científica mas que Duncan (Duncan et al., 2011) considera um bom serviço online, gratuito e disponível publicamente que deve ser observado como uma alternativa bastante eficaz para a geocodificação.

Alguns dos dados foram georreferenciados num outro serviço online, também de acesso gratuito, o GPSVisualizer e que outros trabalhos anteriores em saúde e clima nesta área geográfica revelaram ser uma opção interessante (Esteves, 2010; Moreira, 2011).

Dos 16323 registos, foram georreferenciados com sucesso 15903 (97.4\%), 5082 (31.1\%) através do ArcGis, 10737 (65.8\%) através do Batchgeo e por fim, 84 (0.5\%) pelo GPSVisualizer. Embora este último apresente um valor baixo não significa que este procedimento seja menos eficaz que os anteriores. Acontece é que estes casos eram de facto os mais graves do ponto de vista da qualidade dos registos das moradas.

A maioria das dificuldades de georreferenciação esteve relacionada com erros nas bases cartográficas e com incorreções nos nomes das ruas ou das freguesias registadas. Por vezes, os nomes registados não são os oficiais mas os nomes pelos quais os utentes as reconhecem. Muitas vezes foram os nomes que em tempos tiveram mas que não correspondem aos atuais.

Sem dúvida que a qualidade dos dados das moradas e a base de acessibilidades são extremamente importantes para que se possa obter um resultado satisfatório. A precisão deste processo depende, portanto, não só da qualidade da base de dados que é utilizada para gerar o georreferenciamento mas também da integridade e exatidão dos endereços fornecidos (Siffel et al., 2006).

\section{Etapa 3- distribuição das patologias diagnosticadas}

Após concluirmos a georreferenciação dos utentes inscritos na USF Nova Via procuramos identificar os indivíduos diagnosticados com pelo menos uma das oito patologias, selecionadas na USF Nova Via, juntamente com os profissionais envolvidos, dentre uma lista total de 26 patologias prioritárias, elaborada pela ARS Norte tendo em conta a prevalência, o significado clínico, custos associados e que merecem uma atenção especial no domínio da prevenção e mitigação (ARSNorte, 2011).

Para esta caracterização, foi necessário recolher os dados de diagnóstico de um outro sistema de informação de acesso restrito, o MIM@UF, para coligir a informação sobre quais os utentes diagnosticados com pelo menos uma das 8 patologias selecionadas - asma, bronquite, demência, diabetes, DPOC, hipertensão, obesidade e excesso de peso e perturbações depressivas. Estes dados foram recolhidos em janeiro de 2012.

Pretendemos, portanto, associar esta informação aos utentes previamente georreferenciados, construindo assim pela primeira vez uma base de dados única para dados registados e manipulados por atores diversos, com interesses muito diferentes, e em sistemas de informação que não interagem entre si.

O tratamento desta base de dados com características tão diversas revelou-se de grande exigência e morosidade, tanto mais que em inúmeros passos foi emergente retroceder para corrigir vários erros inesperados.

Curiosamente, apesar de todos terem um interesse comum - a promoção da saúde e a prevenção da doença na área de Espinho/Gaia - a panóplia de softwares onde cada um drena separadamente a informação não thes permite ter um retorno esclarecedor do contexto em que operam e muito menos uma avaliação dos resultados das suas ações.

O conhecimento da localização dos utentes diagnosticados com estas patologias, neste período, foi considerado fundamental para a atuação dos profissionais de saúde, nomeadamente, dos enfermeiros de família que constituem o nosso foco de atenção neste projeto.

Nesta etapa reforçamos ainda mais a ideia sobre a pertinência do nosso propósito. De fato, durante esta etapa metodológica foi evidente, para nós e para os nossos interlocutores, a necessidade urgente de aliar as competências técnicas em tratamento de bases de dados e em SIG associadas às competências científicas dos geógrafos para que tendo a visão do utilizador se possa desenhar um sistema amigável que otimize a multiplicidades de dados existentes mas não aproveitados. 
Definição de critérios para delimitação das áreas homogéneas

Tendo a caracterização das três dimensões realizada, o território, a população e a saúde, passámos à seleção dos critérios principais a ponderar para a delimitação das áreas. A seleção dos critérios foi elaborada procurando garantir todas as recomendações que nos foram dadas pelos responsáveis, de forma a garantir a melhor e mais equitativa distribuição dos enfermeiros de família na USF Nova Via.

A definição de áreas homogêneas, quaisquer que sejam os critérios para a sua delimitação tem sido, sobretudo no âmbito da geografia, alvo de diversos e infinitas polémicas. São vários os estudos que procuram contribuir para este tema sugerindo metodologias baseadas em procedimentos matemáticos e em análise estatística (Miranda and Ramos, 2004; Manzato and Silva, 2007). Dois procedimentos comummente utilizados são a análise exploratória de dados espaciais e a modelagem espacial.

Qualquer destas metodologias beneficia da possibilidade de serem implementadas em ambiente SIG e por esse motivo procuramos carreá-las para o nosso caso de estudo.

Considerando a informação disponível e o interesse dos profissionais de saúde, entendeu-se que a utilização de metodologias baseadas em técnicas estatísticas não seriam contudo adequadas e portanto optamos por definir a nossa própria metodologia de abordagem o mais possível ajustada à realidade da área em estudo.

Os critérios escolhidos para a delimitação das áreas basearam-se na necessidade de definir i)sete áreas, considerando a disponibilidade de sete enfermeiros na USF, ii) cada área, à responsabilidade de cada um dos enfermeiros disponíveis, deveria ter um número homogéneo de utentes distribuídos por faixa etária e género e consequentemente de valor de unidades ponderadas - representam o grau de exigência de cuidados que requer cada doente- e iii) número homogéneo de famílias de forma a cumprir os requisitos legais que de acordo com o Artigo 9. ${ }^{\circ}$ Decreto-Lei n. ${ }^{\circ}$ 297/2007 de 22 de Agosto cada enfermeiro deve ter entre 300 a 400 famílias na sua área geográfica, e ainda, iv) a dimensão das áreas deveria ser também homogénea bem como v) a sua proximidade à USF.

É importante neste ponto realçar que a metodologia sugerida constituí apenas uma das possibilidades de definição de áreas geográficas de enfermeiros de família embora o projeto SIG utilizado esteja preparado para responder facilmente a qualquer cenarização pretendida de acordo com as preferências de ponderação desejadas.

\section{Delimitação das áreas homogéneas}

Para delimitar as sete áreas geográficas dos enfermeiros de família consideramos os preceitos legais e procuramos garantir equidade na diversidade e no grau de exigência da população alvo da atenção destes profissionais de saúde. Assim, a busca das sete áreas que garantiam a melhor e mais equitativa distribuição dos enfermeiros de família na USF Nova Via foi elaborada procurando garantir todas as recomendações que nos foram dadas pelos responsáveis quanto ao grau de exigência de cada tipologia de utente e ao mesmo tempo, as condicionantes do território e as matrizes culturais e socioeconómicas.

Em primeiro lugar procuramos a coincidência geográfica entre as condições biogeofísicas, socioeconómicas e as patologias associadas. Depois, procedemos à espacialização dos dados. Por último, iniciamos uma série de reflexões retroativas que nos facilitaram, em ambiente SIG, melhorar progressivamente as condições de equidade pretendidas.

Para delimitar as áreas de forma equitativa de acordo com os critérios definidos recorremos a um conjunto de ferramentas em software ArcGis que nos permitiram atingir o nosso objetivo.

Utilizamos a ferramenta "Create Thiessem Polygons" para criar polígonos a partir dos pontos dos utentes georreferenciados e de seguida a ferramenta "Near" para definir a proximidade dos polígonos gerados à USF e ainda a ferramenta "Sort" para ordenar os polígonos de acordo com a proximidade à USF. Agrupamos depois as áreas de acordo com os valores máximos permitidos, tanto para o número de utentes e valor de unidades ponderadas como para o número de famílias, de forma a conseguirmos uma distribuição o mais homogênea possivel respeitando os critérios selecionados.

Utilizamos, portanto, ferramentas como o "Create Thiessem Polygons, o "Near" e o "Sort" para calcular a proximidade dos dos utentes à USF. De seguida, de forma a conseguirmos uma distribuição o mais homogênea possível, agrupamos as áreas de acordo com os valores máximos permitidos para os critérios definidos, o número de utentes e valor de unidades ponderadas, o número de famílias.

De seguida, foi necessário reajustar as áreas pelo limite das subsecções já que é esta a unidade administrativa com maior detalhe da informação fornecida pelo INE 2011 abrangendo, geralmente, um bairro ou uma área residencial. Sendo o nosso objetivo a delimitação de áreas para a distribuição de enfermeiros de família, é indispensável que na sua atuação de acompanhamento familiar, estes profissionais, possam também conhecer e compreender as relações de vizinhança e por isso será vantajoso que um enfermeiro possa ficar responsável por toda a área correspondente às subsecções e a envolvente de cada família, para ter um conhecimento mais abrangente e profundo da população, e do contexto em que os utentes residem. 
Procuramos ainda avaliar a equidade na diversidade do perfil de utente verificando a distribuição por género e grupo etário.

O primeiro resultado automático, produzido pela ferramenta SIG quando procuramos criar uma repartição equitativa tendo em conta a área de atuação, pareceu-nos inadequado para a resolução da nossa questão-problema, isto porque, ao privilegiar a proximidade à USF Nova Via, este automatismo SIG delimitou de fato áreas homogéneas polarizadas na USF Nova Via e distribuídas de forma concêntrica em torno dela (fig. 2 - Mapa A). Por isso, a área atribuída a cada enfermeiro de família tinha dimensões muito diversas o que se traduzia numa grande desigualdade na distância-tempo e na distância-custo entre enfermeiros de família.

Deste modo, decidiu-se ajustar, este resultado tentando alterar a forma das áreas para uma simetria triangular expansiva. Usando este método, a USF encontra-se no centro dos limites desenhados que se assemelham a uma divisão dá área em fatias (fig. 2 - Mapa B). Evidentemente que os ângulos dos limites não são exatamente iguais pois os limites das áreas variam mediante a distribuição dos utentes.

Considerando esta reflexão, o resultado final apresenta uma maior homogeneidade entre a dimensão as áreas e a proximidade à USF. Assim, em caso de assistência domiciliária, que será uma das principais funções dos Enfermeiros de Família, todos os envolvidos percorrem uma área semelhante.

A partir desta alternativa, podem ainda ser acrescentados e substituídos critérios, de acordo com a estratégia em concreto, quer do ACES Espinho/Gaia, quer da USF Nova Via e dos enfermeiros prestadores de cuidados.

\section{Armazenamento e Confidencialidade da informação}

Conscientes da sensibilidade da base de dados em análise, optamos pela criação de uma plataforma online, de acesso interno, onde possa ser armazenada toda a informação de interesse para o ACES garantindo níveis de segurança reforçados.

Assim, preparamos uma plataforma sediada na Universidade do Porto que está blindada por níveis de segurança elevadíssimos e que tem uma enorme capacidade de armazenamento.

Esta plataforma WebSIG criada, além de arquivar simultaneamente toda a informação necessária, desde as características biogeofísicas e socioeconómicas até às relativas aos diagnósticos individuais, foi construída em parceria com os serviços de informática da FLUP e com o apoio da ESRI.
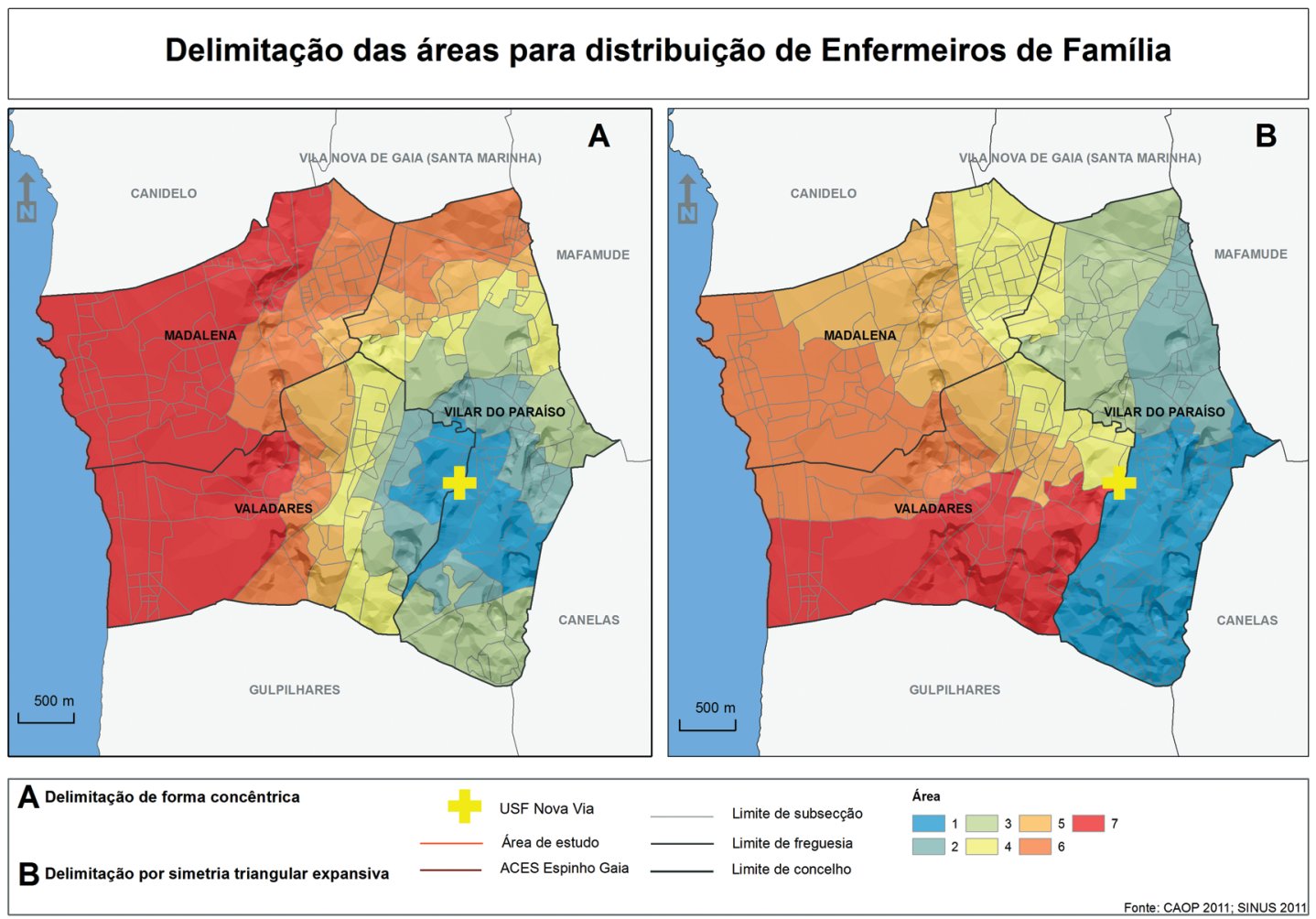

Fig. 2 - Distribuição dos utentes diagnosticados com as patologias selecionadas.

Fig. 2 -Distribution of the users with the diagnosis of the associated pathologies. 
Uma das características fundamentais desta plataforma WebSIG para além da segurança é a versatilidade que possui para definir uma lista considerável de privilégios de acesso.

A criação desta plataforma WebSIG, procurou também demonstrar aos decisores e atores do ACES Espinho/Gaia que é possível permitir aos seus profissionais de saúde armazenar, partilhar e consultar informação sem violar qualquer norma ética e muito menos sem correr riscos no que toca à segurança.

A partir desta plataforma WebSIG poder-se-á relacionar variáveis sociais, económicas, ambientais, climáticas, biogeofísicas, entre outras, atualizar sempre que necessário as bases de dados e acrescentar novas variáveis.

De acordo com a ESRI, o ArcGis Server, que utilizamos, é uma solução SIG para a criação, gestão e distribuição de serviços na Web, suportando aplicações desktop, móveis e de Web de segurança inquestionável (ESRI, 2011).

O trabalho de análise de informação a escalas de grande pormenor, como é o nosso caso, permite beneficiar da mais-valia de ter informação sobre o comportamento real e detalhado das variáveis explicativas de qualquer fenómeno mas força-nos a enveredar por um percurso onde os obstáculos de índole ética e deontológica são muitos e particularmente sensíveis. Mais ainda, quando o fenómeno em análise descreve atributos reservados da saúde e da doença dos seres humanos.

A confidencialidade da informação e a proteção de dados pessoais tem sido internacionalmente e em Portugal progressivamente melhorada pela publicação de normativos legais que procuram, na medida do possível, acompanhar os riscos associados aos avanços da tecnologia (Armstrong et al., 1999). No caso da saúde em particular a preocupação e cuidado está presente em todos os passos de implementação do PNS à semelhança do que acontece noutros países pois os dados trabalhados descrevem atributos da saúde e da doença de seres humanos (Croner et al., 1996).

Assim, este trabalho procura também ilustrar que os SIG podem, se corretamente utilizados, ser uma ferramenta útil para possibilitar melhorias na definição de estratégias locais de saúde e na aplicação das medidas de política previstas lidando com esta informação sem violar os códigos de ética fundamentais.

\section{Resultados}

Do total de 17711 utentes inscritos no ACES Espinho Gaia, foram excluídos da análise 1388 (7,8\%)por residirem fora dos limites do agrupamento. Assim, dos 16323 utentes considerados, o resultado final do processo de georreferenciação atingiu, após uma exaustiva validação, uma taxa de sucesso de $97,4 \%$, o que significa foi possível georreferenciar 15903 utentes. Dos 16323 utentes considerados, 14677 são utentes residentes nas três freguesias constituintes da USF Nova Via, dos quais foram georreferenciados 14356 utentes, (6625 em Vilar do Paraíso, 6575 em Valadares e 1156 na Madalena), o que significa uma taxa de sucesso de $97,8 \%$ para a área da USF (TABELA I).

Considerando que não é útil produção cartográfica quando não se obtém pelo menos $25 \%$ de sucesso no processo de georreferenciação (Harries, 1999), e que a maioria dos estudos apresentados atinge taxas de sucesso entre os 75\% (Drummond, 1995; Faria, 2005; Duncan et al., 2011), as taxas de sucesso atingidas (TABELA I) são excelentes. De referir que para alcançarmos estes elevados valores de sucesso foi necessária uma exausta correção e validação dos dados e dos resultados.

Utilizando os dados georreferenciados do software SINUS e os registos de diagnósticos arquivados no MIM@UF procurámos ilustrar o interesse dos SIG para, associar a informação dispersa em softwares distintos que não permitem a interligação e associação da informação entre si.

Assim, de um total de 10585 registos relativos às oito patologias selecionadas - asma, bronquite, demência, diabetes, DPCO, hipertensão, obesidade e perturbações mentais - foi possível cruzar com 10320 (97,5\%) utentes previamente georreferenciados. Estes 10320 registos distribuem-se por 6251 indivíduos, o que mostra que vários utentes têm mais do que uma patologia diagnosticada (TABELA II).

A principal razão pela qual neste cruzamento em SIG dos diagnósticos e do geoposicionamento dos utentes inscritos

TABela I - Número de utentes inscritos e georreferenciados na USF Nova Via.

TABLE I - Number of registered and georeferenced users at USF Nova Via.

\begin{tabular}{|l|c|c|c|}
\hline & Utentes inscritos & Georreferenciados & Sucesso \\
\hline Total & 17711 & 15903 & $89,8 \%$ \\
\hline Fora Limites do ACES & 1388 & - & - \\
\hline ACES (23 freguesias) & 16323 & 15903 & $97,4 \%$ \\
\hline Nova Via (3 freguesias) & 14677 & 14356 & $97,8 \%$ \\
\hline
\end{tabular}


não atingimos uma taxa de sucesso de 100\% deveu-se ao fato dos dados terem sido recolhidos em sistemas de informação cujo total de utentes não é coincidente (SINUS e MIM@UF). Assim, a análise crítica destes resultados deve ter como pressuposto este constrangimento.

Depois de georreferenciados, os utentes com uma ou mais das 8 patologias selecionadas, a distribuição parece ser muito idêntica em toda a área construída e praticamente sobreponível à distribuição da população (fig. 3).
Como nos propusemos inicialmente, o objetivo deste projeto era definir e delimitar as áreas geográficas que melhor garantiam a equidade para a distribuição dos 7 enfermeiros de família da USF Nova Via. Por isso, todo o SIG foi arquitetado e construído com esta finalidade apesar de, como ficou sobejamente demonstrado, ser uma ferramenta de apoio à elaboração de novas estratégias estando, por isso, apto a dar muitas outras respostas com vista à promoção da saúde e prevenção da doença.

TABeLA II - Número de utentes inscritos com patologia associada.

TABLE II - Number of registered users with associated pathology.

\begin{tabular}{|l|c|c|c|c|c|}
\hline \multicolumn{2}{|c|}{ Utentes por Patologia } & Georreferenciados & Falha & \multicolumn{3}{c|}{$\%$} \\
\hline Asma & 395 & $387(97,8 \%)$ & $8(2,0 \%)$ & 97,8 & 2,0 \\
\hline Bronquite & 112 & $110(98,2 \%)$ & $2(1,1 \%)$ & 98,2 & 1,8 \\
\hline Demência & 74 & $73(98,7 \%)$ & $1(1,3 \%)$ & 98,7 & 1,3 \\
\hline Diabetes & 1163 & $1129(97,1 \%)$ & $34(2,9 \%)$ & 97,1 & 2,9 \\
\hline DPCO & 190 & $188(98,9 \%)$ & $2(1,1 \%)$ & 98,9 & 1,1 \\
\hline Hipertensão & 3352 & $3283(97,9 \%)$ & $69(2,1 \%)$ & 97,9 & 2,1 \\
\hline Obesidade & 4161 & $4047(97,3 \%)$ & $114(2,7 \%)$ & 97,3 & 2,7 \\
\hline Perturbações & 1138 & $1103(96,9 \%)$ & $35(3,1 \%)$ & 96,9 & 3,1 \\
\hline Total & 10585 & $10320(97,5 \%)$ & $265(2,5 \%)$ & 97,5 & 2,5 \\
\hline
\end{tabular}
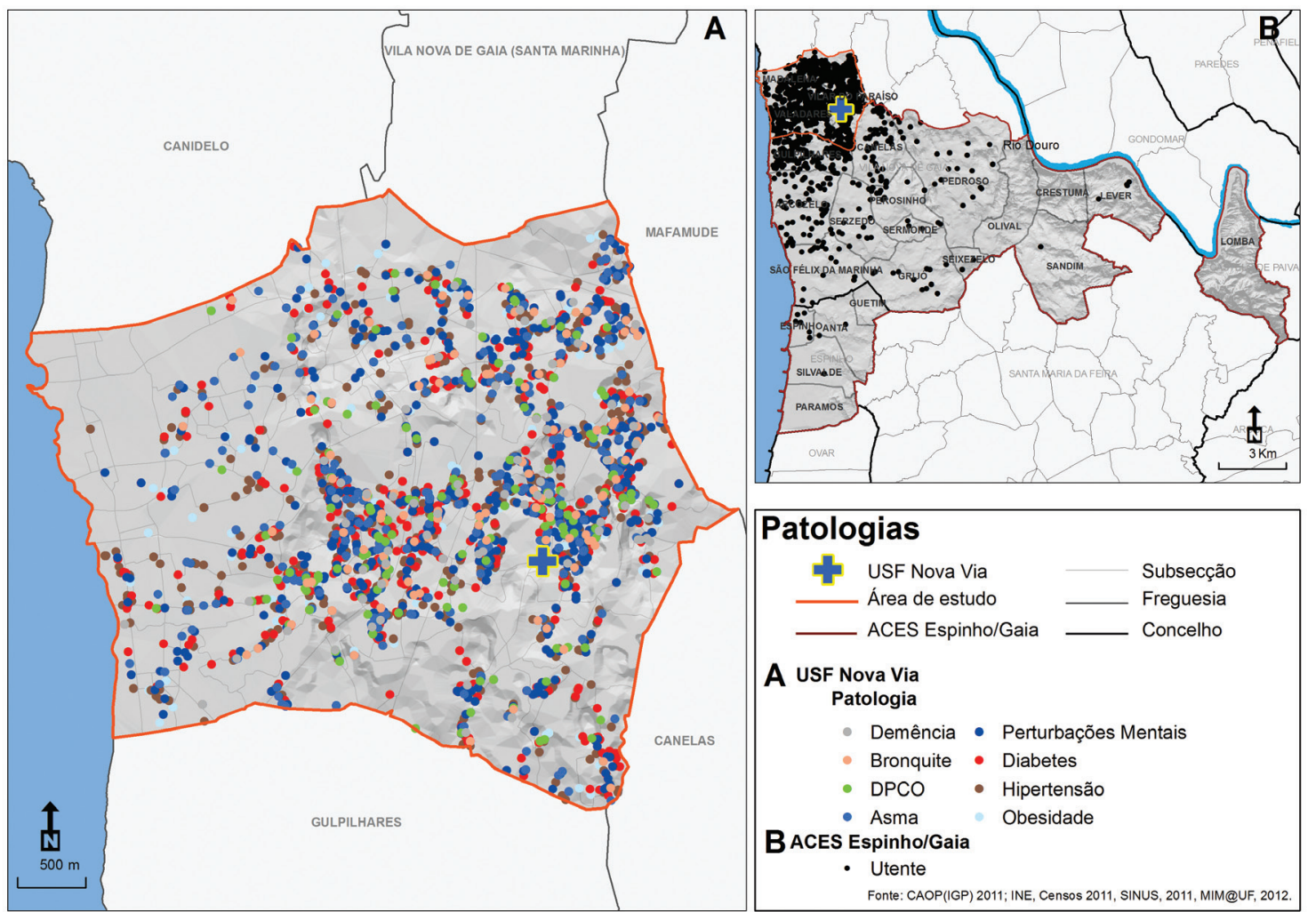

\section{Patologias}

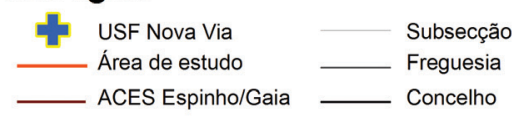

A USF Nova Via Patologia

- Demência - Perturbações Mentais

- Bronquite - Diabetes

- DPCO Hipertensão

- Asma Obesidade

B ACES Espinho/Gaia

- Utente

Fonte: CAOP(IGP) 2011; INE, Censos 2011, SINUS, 2011, MIM@UF, 2012.

Fig. 3 - Distribuição dos utentes diagnosticados com as patologias selecionadas.

Fig. 3 - Distribution of the users with the diagnosis of the associated pathologies. 
De acordo com as etapas metodológicas descritas anteriormente, o resultado atingido pareceu-nos poder vir a ser uma hipótese bastante razoável para distribuir enfermeiros de família por área geográfica embora a partir desta possam e devam ainda ser acrescentados outros critérios de acordo com a estratégia em concreto quer do ACES Espinho/Gaia, quer da USF Nova Via, quer dos enfermeiros prestadores de cuidados (fig. 4).

Para já, esta proposta respeita a equidade quanto ao valor de unidades ponderadas, ao número de utentes, à distribuição por género e grupo etário, à dimensão e às distâncias- assim como algumas características quanto à diversidade biogeofísica e sócio económica (TABELa I e TABeLA IV).

As 7 áreas geográficas sugeridas são também semelhantes quanto às características altimétricas, aos declives, às exposições das vertentes (TABELA IV), e razoavelmente idênticas quanto à distribuição das 8 patologias utilizadas para este exercício (TABELA V).

É importante realçar que a metodologia sugerida constituí apenas uma das possibilidades de definição de áreas geográficas de enfermeiros de família mas o SIG foi preparado para responder facilmente a qualquer cenarização pretendida de acordo com as preferências de ponderação desejadas para esta área geográfica.

\section{Conclusão}

A partir dos resultados obtidos pretendemos principalmente melhorar as condições para o conhecimento eficaz das relações entre a saúde e as características biogeofísicas e socioeconómicas em que as pessoas vivem. Desejamos ainda salientar e fortalecer a importância dos SIG no apoio à tomada de decisão tanto nos cuidados de saúde primários como também no planeamento urbano. Isto porque embora o produto final deste projeto interesse especialmente e no imediato aos responsáveis pela organização do serviço de saúde e pela manutenção da saúde pública, é também verdade que pode suscitar, ao nível dos decisores sobre o território, outras opções de localização de pessoas e atividades mais sustentáveis.

Ao mesmo tempo contribuiremos para que a tomada de decisões seja realizada em cenários de menor incerteza e possam conduzir a medidas, projetos e ações mais assertivas e eficazes no que toca à promoção de maiores ganhos em saúde.

O nosso contributo científico, no âmbito da exploração das potencialidades dos SIG para o apoio à tomada de decisão, circunscreveu-se sobretudo à criação e adaptação de procedimentos metodológicos nos
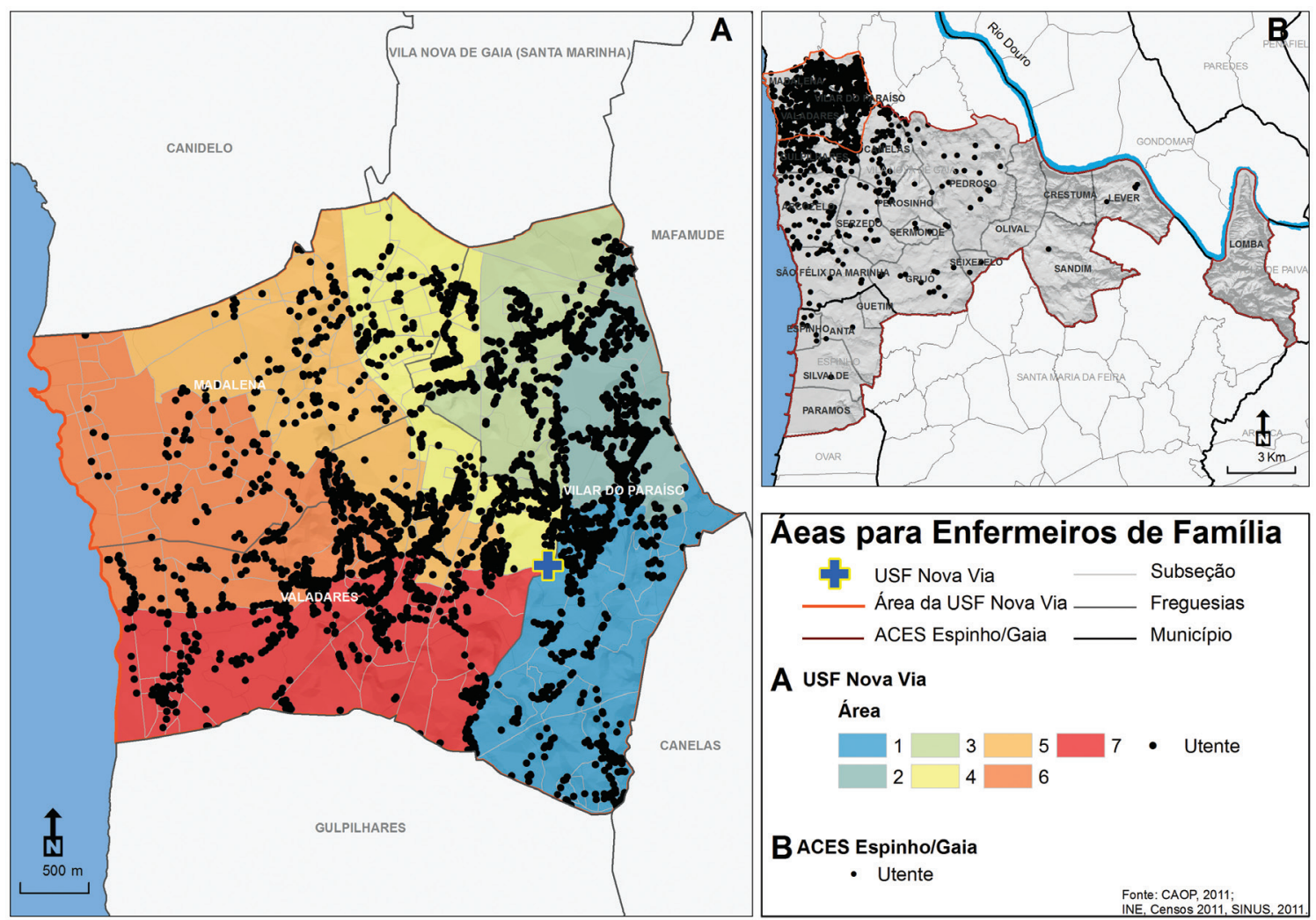

\section{Áeas para Enfermeiros de Família}

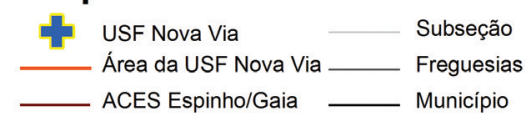

A USF Nova Via

Área

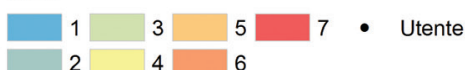

B ACES Espinho/Gaia

- Utente

Fonte: CAOP, 2011:

Fig. 4 - Áreas para distribuição dos enfermeiros de família.

Fig. 4 - Areas for the family nurses distribution. 
RISCOS - Associação Portuguesa de Riscos, Prevenção e Segurança

TABELA III - Distribuição das variáveis, resultante do mapa da fig. 3.

$T_{A B L E}$ III - Variables distribution, resulting from the map of fig. 3.

\begin{tabular}{|c|c|c|c|c|c|c|c|}
\hline & Área 1 & Área 2 & Área 3 & Área 4 & Área 5 & Área 6 & Área 7 \\
\hline Unidades Ponderadas & 2592.5 & 2600.5 & 2617.5 & 2584 & 2606 & 2587.5 & 2581 \\
\hline Utentes & 2041 & 2104 & 2039 & 2015 & 2092 & 2062 & 2003 \\
\hline Homens & 977 & 1041 & 957 & 968 & 976 & 997 & 954 \\
\hline$\%$ & 47.9 & 49.5 & 46.9 & 48.0 & 46.7 & 48.4 & 47.6 \\
\hline Mulheres & 1064 & 1063 & 1082 & 1047 & 1116 & 1065 & 1049 \\
\hline$\%$ & 52.1 & 50.5 & 53.1 & 52.0 & 53.3 & 51.6 & 52.4 \\
\hline 0 a 6 anos & 98 & 118 & 100 & 116 & 156 & 121 & 95 \\
\hline$\%$ & 4.8 & 5.6 & 4.9 & 5.8 & 7.5 & 5.9 & 4.7 \\
\hline 7 a 64 anos & 1534 & 1631 & 1513 & 1475 & 1578 & 1558 & 1480 \\
\hline$\%$ & 75.2 & 77.5 & 74.2 & 73.2 & 75.4 & 75.6 & 73.9 \\
\hline 65 a 74 anos & 222 & 190 & 221 & 250 & 202 & 219 & 223 \\
\hline$\%$ & 10.9 & 9.0 & 10.8 & 12.4 & 9.7 & 10.6 & 11.1 \\
\hline$>75$ anos & 187 & 165 & 205 & 174 & 156 & 164 & 205 \\
\hline$\%$ & 9.2 & 7.8 & 10.1 & 8.6 & 7.5 & 8.0 & 10.2 \\
\hline
\end{tabular}

$\mathrm{x}$ - valor mínimo

x- valor máximo

TABela IV - Distribuição das características biogeofísicas e sociais.

TABLE IV - Distribution of the biogeophysical and social characteristics.

\begin{tabular}{|c|c|c|c|c|c|c|c|}
\hline & Área 1 & Área 2 & Área 3 & Área 4 & Área 5 & Área 6 & Área 7 \\
\hline Área $\mathrm{Km}^{2}$ & 2.31 & 1.15 & 1.56 & 1.77 & 2.37 & 3.15 & 2.79 \\
\hline Mínima & 0.0006 & 0.0011 & 0.0019 & 0.0023 & 0.0022 & 0.0002 & 0.0034 \\
\hline Máxima & 0.2282 & 0.3059 & 0.3187 & 0.1591 & 0.2651 & 0.2941 & 0.6968 \\
\hline Densidade Pop. Média & 3455 & 9318 & 5688 & 5792 & 4405 & 3428 & 2694 \\
\hline Mínima & 44.7 & 10381 & 526 & 2420 & 1335 & 12 & 786 \\
\hline Máxima & 16531 & 45182 & 17896 & 44735 & 12806 & 30946 & 15262 \\
\hline Residentes & 3278 & 4668 & 4400 & 6289 & 6312 & 6216 & 3433 \\
\hline Mínima & 4 & 49 & 1 & 8 & 3 & 1 & 3 \\
\hline Máxima & 370 & 964 & 378 & 678 & 817 & 393 & 663 \\
\hline Edificado & 929 & 808 & 835 & 1376 & 1508 & 1801 & 943 \\
\hline Mínima & 2 & 3 & 1 & 3 & 1 & 1 & 1 \\
\hline Máxima & 89 & 175 & 74 & 65 & 110 & 109 & 156 \\
\hline Alojamentos & 1452 & 2124 & 2132 & 3013 & 2724 & 3123 & 1551 \\
\hline Mínima & 2 & 18 & 1 & 3 & 1 & 1 & 1 \\
\hline Máxima & 160 & 424 & 188 & 292 & 318 & 186 & 233 \\
\hline Famílias & 1229 & 1793 & 1746 & 2463 & 2308 & 2353 & 1271 \\
\hline Mínima & 2 & 16 & 1 & 3 & 1 & 1 & 1 \\
\hline Máxima & 138 & 347 & 140 & 248 & 281 & 149 & 209 \\
\hline Distância $(\mathrm{m})$ Média & 865 & 1524 & 1499 & 1784 & 1924 & 2644 & 1805 \\
\hline Mínima & 200 & 498 & 528 & 176 & 405 & 1195 & 289 \\
\hline Máxima & 1791 & 2363 & 2354 & 2908 & 3254 & 3850 & 3177 \\
\hline Altimetria-média & 98 & 127 & 104 & 85 & 59 & 38 & 45 \\
\hline Mínima & 44 & 80 & 65 & 43 & 20 & 0 & 0 \\
\hline Máxima & 149 & 149 & 149 & 102 & 75 & 65 & 100 \\
\hline Declives (\%) Média & 9.43 & 5.79 & 5.97 & 4.37 & 6.17 & 3.78 & 6.59 \\
\hline Exposição & Oeste & Oeste & Oeste & Oeste e Sul & Oeste & Oeste & Oeste \\
\hline
\end{tabular}


TABELA V - Distribuição do número de utentes com patologia associada.

$T_{A B L E} V$ - Users distribution with the associated pathology.

\begin{tabular}{|l|c|c|c|c|c|c|c|}
\hline & Área 1 & Área 2 & Área 3 & Área 4 & Área 5 & Área 6 & Área 7 \\
\hline Asma & 46 & 55 & 66 & 52 & 59 & 62 & 47 \\
\hline Bronquite & 17 & 19 & 18 & 15 & 19 & 11 & 11 \\
\hline Demencia & 12 & 10 & 13 & 10 & 9 & 5 & 14 \\
\hline Diabetes & 171 & 128 & 176 & 161 & 157 & 166 & 170 \\
\hline DPOC & 32 & 17 & 26 & 33 & 26 & 29 & 25 \\
\hline Hipertenção & 493 & 426 & 497 & 466 & 425 & 499 & 477 \\
\hline Obesidade & 602 & 556 & 541 & 565 & 578 & 608 & 597 \\
\hline Perturbações & 182 & 156 & 156 & 147 & 154 & 151 & 157 \\
\hline Total & 1555 & 1367 & 1493 & 1449 & 1427 & 1531 & 1498 \\
\hline
\end{tabular}

x- valor mínimo

x-valor máximo

SIG que possibilitem a realização de uma leitura da pluralidade de variáveis envolvidas na definição de áreas geográficas para a distribuição de enfermeiros de família em tempo real e que facilite tanto a tomada decisão como a sua rápida reformulação a partir dos resultados alcançados.

Os métodos utilizados demonstraram-se eficientes para o objetivo proposto, a delimitação de áreas geográficas homogéneas para a distribuição de enfermeiros de famílias para a USF Nova Via. O sucesso obtido pelos procedimentos no cumprimento dos objetivos propostos é ressaltado com o interesse demostrado pelos profissionais de saúde envolvidos neste projeto leva a almejar a implementação real deste SIG no ACES estudado e a adaptação de todo o projeto a outros ACES.

\section{Agradecimentos}

À Fundação para a Ciência e para a Tecnologia (FCT) que financiou ao abrigo do programa Compete - Programa Operacional Factores de Competitividade - a investigação no âmbito do projeto ERA NET URBAN/0001/2009.

\section{Referências bibliográficas}

Armstrong, M. P., Rushton, G. \& Zimmerman, D. L. (1999). Geographically masking health data to preserve confidentiality. Statistics in Medicine, 18, 497-525.

ARSNorte 2011. Linha direta n. ${ }^{\circ} 13$. In: Planeamento, D. D. E. E. (ed.). Departamento de Estudos e Planeamento.

Azevedo, J. R., Oliveira, C., Gaspar, J. D. S. \& Freitas, A. (2012). Geographic Information Systems Applied to Patient Distribution for Family Health Teams in
Primary Health Care. In: Gamboa, E. C. C. M. B. A. C. A. L. N. F. H. (ed.) HEALTHINF. SciTePress.

Bédard, Y., Gosselin, P., Rivest, S., Proulx, M.-G., Nadeau, M., Lebel, G. \& Gagnon, M.-F. (2003). Integrating gis components with knowledge discovery technology for environmental health decision support. International Journal of Medical Informatics, 70, 79-94.

Choo, C. W. (2006). A organização do conhecimento: como as organizações usam a informação para criar significado, construir conhecimento e tomar decisões, Editora SENAC.

Croner, C. M., Sperling, J. \& Broome, F. R. (1996). Geographic information systems (GIS): New perspectives in understanding human health and environmental relationships. Statistics in Medicine, 15, 1961-1977.

Cwhpin (2000). Hamilton, ON: Central West Health Planning Information Network.

Driedger, S. M., Kothari, A., Morrison, J., Sawada, M., Crighton, E. \& Graham, I. (2007). Correction: Using participatory design to develop (public) health decision support systems through GIS. International Journal of Health Geographics, 6, 53.

Drummond, W. J. (1995). Address Matching: GIS Technology for Mapping Human Activity Patterns. Journal of the American Planning Association, 61, 240-251.

Duncan, D. T., Castro, M. C., Blossom, J. C., Bennett, G. G. \& Gortmaker, S. L. (2011). Evaluation of the positional difference between two common geocoding methods. Geospatial Health, 5, 265-273.

Elzubair, R. M. E. A. (2009). Aiding decision making in public health domain using web gis. University Teknologi Malaysi. 
ESRI (2011). Available: http://www.esriportugal.pt/ index.php?cID=381 [Accessed 14/05 2011].

Esteves, F. F. (2010). O contributo dos SIG para compreender a relação entre os episódios extremos de temperatura e de variabilidade térmica na época de transição Primavera-Verão e a ocorrência de enfartes do miocárdio no concelho do Porto. Universidade do Porto.

Faria, A. C. (2005). Determinação das Coordenadas geográficas de Imóveis Urbanos: Desenvolvimento de Aplicativo Computacional - Abordagem exploratória de Geocoding em Gis (Dissertação de Mestrado em Análise Espacial). Pontífica Universidade Católica de Minas Gerais.

Fonseca, L. (2012). Contributo dos SIG para a definição de áreas geográficas para a distribuição de enfermeiros de família - Estudo de caso na USF Nova Via do ACES Espinho/Gaia. Universidade do Porto.

Gao, S. (201)0. Advanced health information sharing with web-based GIS Sheng Canada.

Gudes, O., Pathak, V., Kendall, E. \& Yigitcanlar, T. (2011). Thinking spatially, acting collaboratively: a GIS-based health decision support system for improving the collaborative health-planning practice. Proceedings of the HEALTHINF 2011 : International Conference on Health Informatics.

Harries, K. (1999). Mapping Crime: Principale and Practice. In: Department of Justice, O. J. P., National Institute of Justice (ed.). Washington D.C.

Henessy, D. \& Glandin, L. (2006). The report on the evaluation of the WHO multi-country family health nurse pilot study. Copenhague: WHO.

Kemp, K. K., Sage Publications, I. \& Sage, E. (2008). Encyclopedia of geographic information science [Online]. Los Angeles: SAGE Publications. Available: http://site.ebrary.com/id/10372042.

Kistemann, T., Dangendorf, F. \& Schweikart, J. (2002). New perspectives on the use of Geographical Information Systems (GIS) in environmental health sciences. International Journal of Hygiene and Environmental Health, 205, 169-181.

Manzato, G. G. \& Silva, A. N. R. D. (2007). Uma estrutura conceitual para a definição de regiões urbanas homogêneas. Anais do XXI Congresso de Pesquisa e Ensino em Transportes, Rio de Janeiro. Rio de Janeiro : Associação Nacional de Pesquisa e Ensino em Transportes.

Martin, C., Curtis, B., Fraser, C. \& Sharp, B. (2002). The use of a GIS-based malaria information system for malaria research and control in South Africa. Health \& Place, 8, 227-236.
Miranda, M. L. \& Dolinoy, D. C. (2005). Using GIS-Based Approaches to Support Research on Neurotoxicants and Other Children's Environmental Health Threats. NeuroToxicology, 26, 223-228.

Miranda, V. P. \& Ramos, R. A. R. (2004). Comparação entre metodologias para a definição de zonas urbanas homogéneas mediante uma aplicação ao noroeste de Portugal. Associação Portuguesa de Geógrafos.

MonteirO, A., Carvalho, V., Velho, S. \& Sousa, C. (2012 $\stackrel{a}{a})$. Assessing and monitoring urban resilience using COPD in Porto. Science of the Total Environment.

Monteiro, A., Fonseca, L., Almeida, M., Sousa, M., Velho, S. \& Carvalho, V. (2012b). Atlas da Saúde e da Doença - vulnerabilidades climáticas e socioeconómicas na Grande Área Metropolitana do Porto e Concelho do Porto., Porto, Portugal.

Moreira, M. E. G. (2011). Os contextos biogeofísicos e socioeconómicos portuenses e o agravamento da saúde de indivíduos com ACV, Dispeneia \& Asma e Dor Torácica, expresso pelas entradas diárias na urgência do HGSA (2005-2008). Universidade do Porto.

Ray, N. and S. Ebener. Accessmod3. Physical Accessibility to Health Care and Population coverage Modeling User Manual. In WHO, Geneva. 2008.

Riner, M. E., Cunningham, C. \& Johnson, A. (2004). Public health education and practice using geographic information system technology. Public Health Nursing, 21, 57-65.

Siffel, C., Strickland, M. J., Gardner, B. R., Kirby, R. S. $\&$ Correa, A. (2006). Role of geographic information systems in birth defects surveillance and research. Birth Defects Research Part a-Clinical and Molecular Teratology, 76, 825-833.

Snow, J. (1849). On the Pathology and Mode of Communication of Cholera.

Taylor, P. J. \& Overton, M. (1991). Further Thoughts on Geography and Gis - a Preemptive Strike. Environment and Planning A, 23, 1087-1090.

Vaughan-Cole, B., Johnson, M. A., Malone, J. A. \& Walker, B. L. 1998. Family nursing pratice. W.B. Saunders Philadelphia.

WHO - WORLD HEALTH ORGANIZATION (1998). Health 21: An introdution to the health for all policy framework for the WHO European Region. Copenhagen: WHO.

WHO - WORLD HEALTH ORGANIZATION (2000). Munich Declaration: Nurses and midwives: a Force for Health, 2000 Copenhagen, Denmark: WHO Regional Office for Europe. 